\title{
ERRATA
}

\section{Seismic moment of the 1891 Nobi, Japan, earthquake estimated from historical seismograms}

\author{
E. Fukuyama, I. Muramatu, and T. Mikumo
}

Earth Planets Space, Vol. 59, No. 6, pp. 553-559, 2007

At the proof stage, Table 1 was accidentally omitted, and should be as follows.

Table 1. Fault Parameters for the 1891 Nobi Earthquake (modified from Mikumo and Ando, 1976).

\begin{tabular}{cccccc}
\hline Segment & $\begin{array}{c}\text { Strike } \\
(\text { Ndeg.W })\end{array}$ & $\begin{array}{c}\text { Dip } \\
(\text { deg. })\end{array}$ & $\begin{array}{c}\text { Rake } \\
(\text { deg. })\end{array}$ & $\begin{array}{c}\text { Length } \\
(\mathrm{km})\end{array}$ & $\begin{array}{c}\left.\text { Depth range } *^{*}\right) \\
(\mathrm{km})\end{array}$ \\
\hline $\mathrm{a}-\mathrm{a}^{\prime}$ & 40 & 90 & 45 & 20 & $0-15$ \\
$\mathrm{a}^{\prime}-\mathrm{b}$ & 30 & 90 & 45 & 18 & $0-15$ \\
$\mathrm{~b}-\mathrm{c}$ & 28 & 90 & 0 & 17 & $0-15$ \\
$\mathrm{c}-\mathrm{d}$ & 68 & 90 & 45 & 32 & $0-15$ \\
$\mathrm{c}-\mathrm{e}(*)$ & $24 *$ & 90 & 45 & $35^{*}$ & $1-15$ \\
\hline
\end{tabular}

$(*)$ assumed 